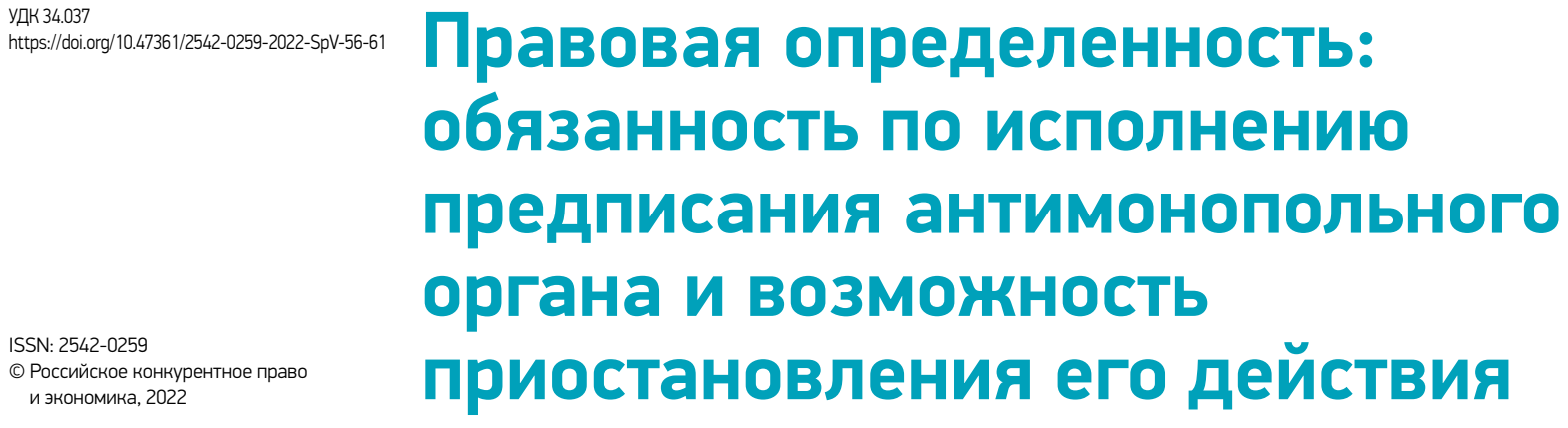

Павлухина О.А., Адвокатское бюро «АРТ ДЕ ЛЕКС», 101000, Россия, г. Москва, Покровский бульвар, д. 4/17, стр. 1 , оф. 26

\begin{abstract}
Аннотация
Предписания, выдаваемые антимонопольным органом, как по результатам рассмотрения дел о нарушении антимонопольного законодательства, так и по результатам рассмотрения жалоб при организации и проведении закупок в соответствии с Федеральным законом от 18.07.2011 № 223-ФЗ «О закупках товаров, работ, услуг отдельными видами юридических лиц», в безусловном и императивном порядке должны подлежать исполнению лицами, в чей адрес они выданы.

В статье исследован актуальный вопрос о неприостановлении действия предписания антимонопольного органа, выданного по результатам рассмотрения жалоб на нарушение процедуры торгов, в случае его судебного оспаривания, а также ответственности за его неисполнение.
\end{abstract}

Ключевые слова: антимонопольный контроль, порядок рассмотрения антимонопольным органом жалоб, нарушение процедуры торгов, предписания антимонопольного органа, приостановление действия предписания, обеспечение заявленных требований, Закон о защите конкуренции, ответственность за неисполнение предписания.

Для цитирования: Павлухина О.А. Правовая определенность: обязанность по исполнению предписания антимонопольного органа и возможность приостановления его действия // Российское конкурентное право и экономика. 2022. SpV. C. 56-61, https://doi.org/10.47361/2542-0259-2022-SpV-56-61

Автор заявляет об отсутствии конфликта интересов. 


\section{Legal Certainty: the Obligation to Comply with the Order of the Antimonopoly Authority and the Possibility of Suspending its Action}

Oksana A. Pavlukhina, ART DE LEX,

Pokrovsky Boulevard, off. 26, bldg 1, 4/17, Moscow, 101000, Russia

\begin{abstract}
Instructions issued by the antimonopoly body, both as a result of consideration of cases on violation of antimonopoly legislation, and as a result of consideration of complaints when organizing and conducting purchases in accordance with Federal Law No. legal entities, in an unconditional and imperative manner must be subject to execution by the persons to whom they were issued. The article examines the topical issue of not suspending the order of the antimonopoly authority issued based on the results of consideration of complaints about violation of the bidding procedure, in the event of its judicial challenge and liability for its failure.
\end{abstract}

Keywords: antimonopoly control, the procedure for considering complaints by the antimonopoly authority, violation of the bidding procedure, orders of the antimonopoly authority, suspension of the order, ensuring the stated requirements, the Law on the Protection of Competition, liability for non-compliance with the order.

For citation: Pavlukhina O.A. Legal certainty: the obligation to comply with the order of the antimonopoly authority and the possibility of suspending its action // Russian Competition Law and Economy. 2022;(SpV):56-61 (In Russ.), https://doi.org/10.47361/2542-0259-2022-SpV-56-61

The author declare no conflict of interest.

\section{Введение}

$\mathrm{H}$ еобходимость в настоящем исследовании вызвана неопределенностью в вопросе приостановления действия выдаваемого ФАС России или ее территориальными управлениями предписания по результатам рассмотрения жалоб на нарушение процедуры торгов и порядка заключения договоров в случае его судебного оспаривания. Эта неопределенность относится исключительно к пониманию лицами, на которых непосредственно распространяют свое действие принятое антимонопольным органом решение и выданное предписание, оснований и условий приостановления действия соответствующего предписания.

Рассмотрение жалоб на действия (бездействие) юридического лица, организатора торгов, оператора электронной площадки комиссии при организации и проведении закупок в соответствии с Федеральным законом от 18.07.2011 № 223-Ф3 «0 закупках товаров, работ, услуг отдельными видами юридических лиц»' (далее - Закон о закупках) осуществляется ФАС России и ее территориальными управлениями в порядке, уста-

\footnotetext{
См.: Федеральный закон от 18.07.2011 № 223-Ф3 «0 закупках товаров, работ, услуг отдельными видами юридических лиц» (ред. от 01.07.2021) // Собрание законодательства РФ, 25.07.2011, № 30 (ч. 1), C. 4571
} 
новленном ст. $18^{1}$ Федерального закона от 26.07.2006 № 135-Ф3 «0 защите конкуренции»² (далее - Закон о защите конкуренции).

По результатам рассмотрения жалобы антимонопольный орган выносит решение и при необходимости выдает лицу, в чьих действиях установлено нарушение законодательства о закупках, обязательное к исполнению предписание, которые в соответствии с ч. 23 ст. 18' Закона о защите конкуренции могут быть оспорены в судебном порядке.

При этом согласно п. 45 постановления Пленума Верховного Суда Российской Федерации от 04.03.2021 №2 «О некоторых вопросах, возникающих в связи с применением судами антимонопольного законодательства» ${ }^{3}$ (далее - Постановление №2) суды при рассмотрении заявлений о признании недействительными актов антимонопольного органа должны принимать во внимание соблюдение государственным органом порядка реализации контрольно-надзорных функций, а также привело ли или могло ли привести допущенное несоблюдение установленного Законом о защите конкуренции порядка к нарушению прав и законных интересов соответствующего лица.

Не секрет, что на сегодня оспаривание актов антимонопольного органа является стандартным инструментом защиты заказчиками, осуществляющими закупочные процедуры, или участниками данных процедур в рамках Закона о закупках своих прав и законных интересов в случаях, когда выдаваемые предписания негативно влияют на их закупочную деятельность или на возможность принять участие в закупках.

Зачастую выполнение определенных действий, указанных в предписании антимонопольного органа, может повлечь для заказчика, осуществляющего закупочные процедуры, необратимые последствия в виде аннулирования закупки. В этой связи заказчик не торопится исполнять властные указания антимонопольного органа, рассчитывая на признание судом решения и предписания антимонопольного органа недействительными, как принятых вразрез с положениями действующего законодательства о закупках.

При этом заказчик, обращаясь в арбитражный суд с заявлением о признании недействительными ненормативных правовых актов антимонопольного органа (решения и предписания), с полной уверенностью полагает, что в силу положений ч. 2 ст. 52 Закона о защите конкуренции действие предписания будет приостановлено до

2 См.: Федеральный закон от 26.07.2006 № 135-Ф3 «0 защите конкуренции» (ред. 17.02.2021) // Собрание законодательства РФ, 2006. № 31 (ч. 1). С. 3434.

3 См.: Постановление Пленума Верховного Суда РФ от 04.03.2021 № 2 «О некоторых вопросах, возникающих в связи с применением судами антимонопольного законодательства» // СПС КонсультантПлюс (Дата обращения: 16.12.2021). момента вступления в законную силу решения суда, что позволит ему не исполнять выданное предписание.

Вместе с тем заказчик сталкивается с такой ситуацией, что вместо приостановления действия предписания антимонопольный орган возбуждает дело об административном правонарушении за неисполнение властного указания государственного органа и привлекает заказчика к административной ответственности.

В настоящей статье автором предпринимается попытка сравнительно-правового анализа процедуры рассмотрения дел о нарушении антимонопольного законодательства, в рамках так называемой «короткой» процедуры рассмотрения жалоб по ст. 181 Закона о защите конкуренции в целях ответа на вопрос о процессуальной необходимости синхронного применения отдельных элементов данных процедур, в частности, в контексте приостановления действия предписаний в связи с их обжалованием.

\section{Порядок — от общей нормы к специальной}

Положениями Закона о защите конкуренции определяются полномочия антимонопольного органа по рассмотрению жалоб на нарушение процедуры обязательных в соответствии с законодательством Российской Федерации торгов (п. $4^{2}$ 4. 1 ст. 23 Закона о защите конкуренции), а также регламентируется порядок их рассмотрения (ст. 18' Закона о защите конкуренции).

При рассмотрении жалоб в рамках ст. 18' Закона о защите конкуренции в том числе рассматривается спор участника торгов или лиц, изъявивших желание принять участие в торгах, с одной стороны, и организатора торгов, конкурсной или аукционной комиссии и (или) оператора электронной площадки, с другой стороны.

Процедура рассмотрения жалоб в соответствии со ст. $18^{1}$ Закона о защите конкуренции отвечает всем признакам административно-юрисдикционного процесса [1, с. 48] и не предусматривает возбуждение и рассмотрение антимонопольным органом дела о нарушении антимонопольного законодательства.

Специальная процедура возбуждения и рассмотрения дел о нарушении антимонопольного законодательства регламентируется гл. 9 Закона о защите конкуренции, Административным регламентом ФАС России по исполнению государственной функции по возбуждению и рассмотрению дел о нарушении антимонопольного законодательства, утвержденным приказом ФАС России от 25.05.2012 № $339^{4}$.

\footnotetext{
См.: Приказ ФАС России от 25.05.2012 № 339 (ред. от 16.02.2016) «06 утверждении административного регламента Федеральной антимонопольной службы по исполнению государственной функции по возбуждению и рассмотрению дел о нарушениях антимонопольного законодательства Российской Федерации» // Бюллетень нормативных актов федеральных органов исполнительной власти. 2013. № 8.
} 
Статьей $18^{1}$ Закона о защите конкуренции установлен самостоятельный ускоренный порядок рассмотрения жалоб, который существенно отличается от процедуры рассмотрения дел о нарушении антимонопольного законодательства, в связи с чем положения гл. 9 Закона о защите конкуренции не могут быть применены к указанной процедуре.

Как отмечает А.В. Молчанов, процедура рассмотрения жалобы на действия (бездействие) организатора торгов, оператора электронной площадки при организации и проведении торгов предполагает коллегиальность (рассмотрение жалобы осуществляется комиссией), состязательность и в целом имеет сходство с процедурой рассмотрения дела о нарушении антимонопольного законодательства, предусмотренной гл. 9 Закона о защите конкуренции, однако она не входит в гл. 9 Закона о защите конкуренции [2].

Вместе с тем как по результатам рассмотрения дела о нарушении антимонопольного законодательства, так и по результатам рассмотрения жалоб в порядке ст. 181 Закона о защите конкуренции антимонопольный орган может принять решение о необходимости выдать обязательное к исполнению предписание.

Возможность выдачи предписания ответчику по делу о нарушении антимонопольного законодательства предусмотрена ст. 50 Закона о защите конкуренции, а положения ст. 51 и ст. 52 Закона о защите конкуренции регламентируют порядок исполнения и обжалования такого предписания. Выдача предписания по результатам рассмотрения жалоб в порядке, предусмотренном ст. $18^{1}$ Закона о защите конкуренции, регламентирована ч. 20 указанной статьи.

Безусловно, законность решения и предписания антимонопольного органа может быть подвергнута сомнению и оспорена заинтересованными лицами в течение трех месяцев со дня их принятия в арбитражном суде (ч. 23 ст. $18^{1}$ Закона о защите конкуренции). Но важным и отличительным в данном случае обстоятельством является то, что определенные в ст. $18^{1}$ Закона о защите конкуренции положения не содержат аналогичного ч. 2 ст. 52 Закона о защите конкуренции положения о приостановлении исполнения предписания антимонопольного органа в случае его судебного оспаривания до дня вступления решения арбитражного суда в законную силу.

Указанное свидетельствует о том, что положения ст. 52 и ст. 18' Закона о защите конкуренции соотносятся как общая и специальная нормы. При этом исходя из общих принципов права при наличии нормы, специально регулирующей те или иные правоотношения, общая норма не подлежит применению5 ${ }^{5}$ что исключает

5 См.: Решение Верховного Суда РФ от 10.11.2020 № АКПИ20-632 «Об отказе в удовлетворении заявления о признании недействующим п. 1 Письма ФАС России от 12.09.2019 № ИА/79982/19» // СПС КонсультантПлюс (Дата обращения: 15.11.2021). возможность приостановления действия предписания, выданного в порядке ст. $18^{1}$ Закона о защите конкуренции.

Таким образом, ст. 18 Закона о защите конкуренции установлен особый самостоятельный порядок рассмотрения антимонопольным органом жалоб на нарушение процедуры торгов и нарушение порядка заключения договоров, который не относится к процедуре рассмотрения дел о нарушении антимонопольного законодательства в порядке гл. 9 Закона о защите конкуренции.

Указанное также следует из положений п. 45 Постановления № 2, согласно которым жалобы участников закупки на действия (бездействие) заказчика при проведении по правилам Закона о закупках конкурентных закупок подлежат рассмотрению в порядке ст. $18^{1}$ Закона о защите конкуренции, по основаниям, установленным ч. 10 ст. 3 Закона о закупках, а не по правилам гл. 9 Закона о защите конкуренции.

В этой связи исполнение предписания, выданного на основании ч. 20 ст. 18' Закона о защите конкуренции, может быть приостановлено лишь в случае принятия судом соответствующих обеспечительных мер ${ }^{6}$ в порядке гл. 8 Арбитражного процессуального кодекса Российской Федерации ${ }^{7}$.

Однако на практике арбитражные суды, оценивая содержание заявления о принятии обеспечительных мер в виде приостановления исполнения предписания, зачастую отказывают в принятии указанных мер, так как приходят к выводу о том, что лицом не доказано, что непринятие мер по обеспечению иска приведет к невозможности исполнить судебный акт в случае удовлетворения заявленных требований или причинения значительного ущерба заявителю8 . $^{\circ}$

Так, согласно п. 13 постановления Пленума Высшего Арбитражного Суда Российской Федерации (ВАС РФ) от

6 См.: Определение Верховного Суда РФ от 23.12.2020 № 307ЭС20-16192, решение Верховного Суда РФ от 10.11.2020 № АКПИ20-632, Письмо ФАС России от 12.09.2019 № ИА/79982/19 «О рассмотрении жалоб на действия организатора торгов, оператора электронной площадки в порядке статьи 18.1 Закона о защите конкуренции» // СПС КонсультантПлюс (Дата обращения: 15.11.2021).

7 См.: Арбитражный процессуальный кодекс Российской Федерации от 24.07.2002 №95-Ф3 (ред. от 01.07.2021, с изм. от 22.07.2021) // Собрание законодательства РФ, 29.07.2002, № 30, C. 3012 .

8 См.: Постановление АС Поволжского округа от 17.12.2018 № Ф06-40825/2018 по делу № А12-22789/2018, определение АС Калининградской области от 21.01.2019 по делу № A21-676/2019, определение АС города СанктПетербурга и Ленинградской области от 21.10.2019 по делу № А56-111641/2019 // СПС КонсультантПлюс (Дата обращения: 15.11.2021) 
09.12.2002 № $11^{9}$ арбитражные суды не должны принимать обеспечительные меры, если заявитель не обосновал причины обращения с заявлением об обеспечении требования конкретными обстоятельствами, подтверждающими необходимость принятия обеспечительных мер, и не представил доказательства, подтверждающие его доводы.

Таким образом, заказчик или иное лицо, в чей адрес выдано предписание, должны прикладывать максимальные усилия для того, чтобы доказать суду необходимость и важность применения обеспечительных мер в виде приостановления действия предписания. В противном случае предписание подлежит обязательному исполнению еще до момента вступления решения суда в законную силу.

\section{Меры административного воздействия за неисполнение предписания}

Как уже было отмечено ранее, к полномочиям антимонопольных органов (с учетом взаимосвязанных положений п. 2 ст. 22, пп. 2-3.1 ч. 1 ст. 23 и ч. 4 ст. 41 Закона о защите конкуренции) в том числе относится выдача хозяйствующим субъектам и иным лицам предписаний ${ }^{10}$.

Предписание выдается антимонопольным органом в целях устранения (прекращения) выявленных им нарушений законодательства на основании и во исполнение решения антимонопольного органа. Следовательно, выдача предписания является реакцией контрольного органа на выявленные нарушения и направлена прежде всего на восстановление режима законности. При этом целью предписания, которое, например, выдается заказчику, является устранение нарушений прав и законных интересов участников закупочной процедуры.

Обязанность по исполнению властных указаний регулятора (предписания) возникает из содержания ст. 36 Закона о защите конкуренции. Отсутствие в Законе о защите конкуренции императивных указаний на обязанность лиц по исполнению предписания нивелировало бы весь институт выдачи предписаний и исключило бы возможность антимонопольной службы пресекать правонарушения и устранять нарушения прав и законных интересов участников закупочной процедуры.

В связи с этим предписание об устранении нарушений порядка проведения торгов является обязательным для

9 См.: Постановление Пленума Высшего Арбитражного Суда Российской Федерации от 09.12.2002 № 11 «О некоторых вопросах, связанных с введением в действие Арбитражного процессуального кодекса Российской Федерации» // СПС КонсультантПлюс (Дата обращения: 20.11.2021).

10 См.: Постановление Пленума Верховного Суда РФ от 04.03.2021 № 2 «О некоторых вопросах, возникающих в связи с применением судами антимонопольного законодательства» // СПС КонсультантПлюс (Дата обращения: 16.12.2021). исполнения, и такая обязательность охраняется нормами Кодекса Российской Федерации об административных правонарушениях (далее - КоАП РФ) ${ }^{11}$ [3]. Указанное свидетельствует о том, что антимонопольный орган при формировании конкретного перечня действий, которые необходимо совершить правонарушителю во благо восстановления конкуренции к четко установленному сроку, должен принимать во внимание, что лицо, в чей адрес выдано предписание, должно иметь возможность его исполнить в полном объеме, т. е. предписание должно являться исполнимым ${ }^{12}$.

Примерами конкретных действий, которые необходимо совершить для исполнения предписания, могут являться: отмена протокола рассмотрения заявок/проведения аукциона; назначение новой даты, времени проведения аукциона/подведения итогов аукциона; продолжение проведения аукциона в соответствии с требованиями Закона о закупках, положения о закупке, документации, и другое. При этом антимонопольный орган в предписании устанавливает обязанность представить до определенной даты подтверждение исполнения предписания.

Данная обязанность антимонопольного органа - выдать именно исполнимое предписание, согласуется с тем, что неисполнение в установленный антимонопольным органом срок обязательных требований по прекращению совершения выявленного по итогам рассмотрения жалобы правонарушения содержит признаки состава административного правонарушения, ответственность за совершение которого предусмотрена ч. $7^{2}$ ст. 19.5 КоАП РФ [4]. Дело об административном правонарушении по факту невыполнения в установленный срок предписания подлежит возбуждению по истечении срока исполнения такого предписания.

Таким образом, неприостановление действия предписания, выданного в порядке ч. 20 ст. 18' Закона о защите конкуренции, в случае его судебного оспаривания и в отсутствие применения обеспечительных мер влечет императивную обязанность лица, в чей адрес оно выдано, исполнить его в установленный антимонопольным органом срок. В противном случае для лица, которое не исполнило предписание, наступает административная ответственность.

11 См.: Кодекс Российской Федерации об административных правонарушениях от 30.12.2001 № 195-Ф3 (ред. от 01.07.2021, с изм. от 09.11.2021) // Собрание законодательства РФ, 07.01.2002, № 1 (ч. 1) // СПС КонсультантПлюс (Дата обращения: 16.11.2021).

12 См.: Определение Верховного Суда РФ от 13.05.2021 №303-ЭС21-5940 по делу № A51-23075/2019, Определение Верховного Суда РФ от 07.12.2020 №307-ЭС20-21049 по делу № А56-51776/2019, решение Арбитражного суда г. Москвы от 25.01.2021 по делу № A40-162583/20-130-1075, решение Арбитражного суда г. Москвы от 27.09.2019 по делу № A40-128322/19-79-1120 // СПС КонсультантПлюс (Дата обращения: 16.11.2021) 


\section{Заключение}

Процедура рассмотрения дел о нарушении антимонопольного законодательства является отличной от процедуры рассмотрения жалоб на нарушение процедуры торгов и порядка заключения договоров, на что также обратил внимание высший орган судебной власти в Постановлении № 2. Но несмотря на то, что как по результатам рассмотрения заявлений, так и по результатам рассмотрения жалоб антимонопольный орган вправе выдать обязательное к исполнению предписание, необходимо понимать, что выданное по «короткой» процедуре предписание не приостанавливает своего действия в случае судебного оспаривания.

Необходимость в приостановлении исполнения предписания ФАС России и ее территориальных управлений до вступления в законную силу решения суда понятна и зачастую обусловлена нежеланием заказчика исполнять конкретные действия антимонопольного органа ввиду несогласия с принятым решением и выданным предписанием.

Единственная возможность приостановить действие предписания, выданного в порядке ч. 20 ст. 18' Закона о защите конкуренции, - обратиться в арбитражный суд с заявлением о принятии обеспечительных мер, предоставив суду достаточные доказательства необходимости и объективности принятия указанных мер. В остальных случаях действие предписания антимонопольного органа в случае его судебного оспаривания не приостанавливается и должно быть в обязательном порядке исполнено в указанный в нем срок. В противном случае лицо, в чей адрес оно выдано, будет подвергнуто мерам административного воздействия в виде применения штрафных санкций.

При этом факт исполнения предписания при оспаривании его законности и исполнимости, с одной стороны, может свидетельствовать о его действительности (на что суды обращают особое внимание) и о бессмысленности дальнейшего оспаривания. С другой стороны, исполнение предписания зачастую является вынужденной мерой, связанной с недопущением привлечения лица к административной ответственности за его неисполнение, и не исключает признание решения и предписания недействительными, что может повлечь необратимые последствия (все совершенные во исполнение предписания действия являлись незаконными как противоречащие действующему законодательству).

В этой связи заказчик или иное лицо, в чей адрес выдано предписание, сталкивается с ситуацией, когда существует прямая обязанность исполнить властное пред- писание государственного органа и в то же время риск признания судом принятого акта недействительным, что нивелирует законность его исполнения.

Таким образом, заказчик в каждом конкретном случае должен принимать для себя взвешенное с правовой точки зрения и вероятных последствий решение касательно исполнения или неисполнения выданного предписания, понимая риски совершения тех или иных дейСтвий.

\section{Литература [References]}

1. Сатышев В.Е. Административное право: Учебное пособие. М.: Омега-Л. 2012. 252 с. [Satyshev V.E. Administrative law: Textbook. M.: Omega-L. 2012. 252 p. (In Russ.)]

2. Процедуры в конкурентном праве / Ю.И. Абакумова, О.Р. Афанасьева, А.В. Борисов [и др.]. М.: Проспект. 2019. 296 с. ISBN 978-5-392-28481-8. DOI 10.31085/9785392284818-2019-296 [Procedures in competition law/ Abakumova Y.I., Afanasyeva O.R., Borisov A.V. [et al.]. M: Prospect. 2019. 296 p. ISBN 978-5-392-28481-8 (In Russ.), DOI 10.31085/9785392284818-2019-296]

3. Башлаков-Николаев И.В. Об обжаловании в антимонопольные органы порядка проведения торгов и заключения договоров по их итогам в соответствии со ст. 18.1 Закона о защите конкуренции: процессуальные аспекты // Законы России: опыт, анализ, практика. 2014. №5. C. 55-60 [Bashlakov-Nikolaev I.V. On appealing bidding procedures and making a contract as a result of bidding procedures to antitrust authorities under art. 181 of the law on competition protection: procedural aspects // Laws of Russia: experience, analysis, practice. 2014;(5):33-60 (In Russ.)]

4. Писенко К.А., Бадмаев Б.Г., Казарян К.В. Антимонопольное (конкурентное) право: учебник // СПС КонсультантПлюс. 2014.313 с. (Дата обращения: 16.11.2021) [Pisenko K.A., Badmaev B.G., Kazaryan K.V. Antimonopoly (competition) law. Textbook // ConsultantPlus. 2014. 313 p. (In Russ.) (Accessed: 16.11.2021)]

\section{Сведения об авторе}

Павлухина Оксана Александровна: руководитель группы практики антимонопольного регулирования Адвокатского бюро «АРТ ДЕ ЛЕКС» o.pavlukhina@artdelex.ru
Статья поступила в редакцию: 30.11.2021

Одобрена после рецензирования: 23.12.2021

Принята к публикации: 27.12.2021

Дата публикации: 08.02.2022
The article was submitted: 30.11 .2021

Approved after reviewing: 23.12.2021

Accepted for publication: 27.12.2021

Date of publication: 08.02.2022 